\title{
Selective Internal Radiation Therapy (SIRT) with yttrium-90 resin microspheres plus standard systemic chemotherapy regimen of FOLFOX versus FOLFOX alone as first-line treatment of non-resectable liver metastases from colorectal cancer: the SIRFLOX study
}

Peter Gibbs ${ }^{1,6^{*}}$, Val Gebski ${ }^{2}$, Mark Van Buskirk ${ }^{3}$, Kenneth Thurston ${ }^{4}$, David N Cade ${ }^{4}$, Guy A Van Hazel ${ }^{5}$ and SIRFLOX Study Group

\begin{abstract}
Background: In colorectal cancer (CRC), unresectable liver metastases are linked to poor prognosis. Systemic chemotherapy with regimens such as FOLFOX (combination of infusional 5-fluorouracil, leucovorin and oxaliplatin) is the standard first-line treatment. The SIRFLOX trial was designed to assess the efficacy and safety of combining FOLFOX-based chemotherapy with Selective Internal Radiation Therapy (SIRT or radioembolisation) using yttrium-90 resin microspheres (SIR-Spheres ${ }^{\oplus}$; Sirtex Medical Limited, North Sydney, Australia).
\end{abstract}

Methods/Design: SIRFLOX is a randomised, multicentre trial of mFOLFOX6 chemotherapy \pm SIRT as first-line treatment of patients with liver-only or liver-predominant metastatic CRC (mCRC). The trial aims to recruit adult chemotherapy-naiive patients with proven liver metastases with or without limited extra-hepatic disease, a life expectancy of $\geq 3$ months and a WHO performance status of 0-1. Patients will be randomised to receive either mFOLFOX6 or SIRT + mFOLFOX6 (with a reduced dose of oxaliplatin in cycles 1-3 following SIRT). Patients in both arms can receive bevacizumab at investigator discretion. Protocol chemotherapy will continue until there is unacceptable toxicity, evidence of tumour progression, complete surgical resection or ablation of cancerous lesions, or the patient requests an end to treatment. The primary endpoint of the SIRFLOX trial is progression-free survival (PFS). Secondary endpoints include: PFS in the liver; tumour response rate (liver and any site); site of tumour progression; health-related quality of life; toxicity and safety; liver resection rate; and overall survival. Assuming an increase in the median PFS from 9.4 months to 12.5 months with the addition of SIRT to mFOLFOX6, recruiting $\geq 450$ patients will be sufficient for $80 \%$ power and $95 \%$ confidence.

Discussion: The SIRFLOX trial will establish the potential role of SIRT + standard systemic chemotherapy in the first-line management of $\mathrm{mCRC}$ with non-resectable liver metastases.

Trial registration: SIRFLOX ClinicalTrials.gov identifier: NCT00724503. Registered 25 July 2008.

Keywords: Metastatic colorectal cancer, Liver metastases, Systemic chemotherapy, SIR-Spheres ${ }^{\circledR}$ microspheres, Selective Internal Radiation Therapy (SIRT)

\footnotetext{
* Correspondence: peter.gibbs@mh.org.au

${ }^{1}$ Royal Melbourne Hospital, Melbourne, Victoria, Australia

${ }^{6}$ Walter and Eliza Hall Institute Medical Research, Melbourne, Australia

Full list of author information is available at the end of the article
} 


\section{Background}

In colorectal cancer (CRC), liver metastases are linked to poor prognosis - death and recurrence are frequently attributable to liver metastases [1-3]. Surgical resection of CRC liver metastases can result in cure, and produces 5 -year survival of $27-39 \%$ and 10-year survival of $12-36 \%$ $[2,4,5]$, as opposed to median survival of approximately 9 months if untreated [6]. However, only $10-20 \%$ of patients with liver metastases from CRC are candidates for such surgery [7-10], and intra-hepatic and extra-hepatic relapse after liver resection is common [11].

Systemic chemotherapy is, therefore, used as first-line treatment in patients with non-resectable liver metastases [12-17], and in some cases can sufficiently down-size the tumour burden in patients with previously inoperable liver metastases so that they may be converted to candidates for potentially curative resection $[18,19]$. Internationally accepted first-line chemotherapy regimens for patients with mCRC include FOLFOX (combination of bolus and infusional 5-fluorouracil [5-FU], leucovorin [LV] and oxaliplatin) and FOLFIRI (combination of bolus and infusional 5-FU, LV and irinotecan). These regimens provide median survival times of 16-20 months [15,20], and the addition of biologic agents, such as bevacizumab and cetuximab, to chemotherapy regimens may enhance progression-free survival (PFS) and overall survival (OS) $[17,21]$.

Selective Internal Radiation Therapy (SIRT or radioembolisation) is an innovative radiation therapy for mCRC, which involves the delivery of SIR-Spheres (Sirtex Medical Limited, North Sydney, Australia), that contain the $\beta$ emitter yttrium-90, into the arterial supply of the liver. These resin microspheres are delivered via a trans-femoral hepatic artery catheter. In a randomised Phase II trial, treatment of mCRC with SIRT plus first-line 5-FU/LV chemotherapy resulted in a longer time-to-progression (18.6 months) compared with 5-FU/LV chemotherapy alone (3.6 months) [22]. A subsequent Phase I clinical trial demonstrated that SIRT combined with FOLFOX4 systemic chemotherapy had acceptable tolerability [23]. In this trial of 20 patients with non-resectable liver metastases from CRC, SIRT was administered on the third or fourth day of the first cycle of first-line chemotherapy. The dose-limiting toxicity was grade $3 / 4$ neutropenia, and the authors suggested the maximum tolerated dose of oxaliplatin was $60 \mathrm{mg} / \mathrm{m}^{2}$ for the first three cycles, with full-dose FOLFOX4 thereafter [23]. Although the primary endpoint of this study was toxicity, the objective response rate according to Response Evaluation Criteria In Solid Tumours (RECIST) was 90\%, two patients (10\%) were down-staged to undergo hepatic resection and median PFS was 9.3 months [23].

These results suggest that the combination of SIRT and FOLFOX systemic chemotherapy warrants further investigation. Consequently, two open-label, randomised, controlled Phase III trials of mFOLFOX $6 \pm$ SIRT as first-line treatment of patients with liver-only or liverpredominant $\mathrm{mCRC}$ were designed with virtually identical protocols (SIRFLOX and FOXFIRE). The primary endpoint of SIRFLOX is a comparison between treatment arms of PFS.

\section{Methods/Design}

The SIRFLOX study will be conducted in accordance with the Declaration of Helsinki, and approval has been obtained from the relevant ethics committees for each participating centre (see Additional file 1 for a list). When the results of the study are reported, CONSORT guidelines will be adhered to.

\section{Eligible population}

The inclusion and exclusion criteria for the SIRFLOX study is summarised in Table 1.

\section{Overview of study design}

SIRFLOX is a randomised, multicentre study of mFOLFOX $6 \pm$ SIRT as first-line treatment of patients with inoperable liver-only or liver-predominant $\mathrm{mCRC}$. In SIRFLOX, the aim will be to recruit a minimum of 450 patients at a minimum of 35 sites in Australia, Europe, Israel, New Zealand and USA. Eligible patients are randomised 1:1 to receive either systemic chemotherapy with 5-FU/LV + oxaliplatin (FOLFOX; control arm) or single-session whole liver SIRT + systemic chemotherapy with 5-FU/LV + oxaliplatin (FOLFOX; intervention arm) (Figure 1). All patients may also receive bevacizumab at the investigator's discretion.

\section{Randomisation and stratification}

When a patient is eligible to participate in the study, randomisation, using the method of minimisation, will be performed using a centralised Study Randomisation Centre at the NHMRC Clinical Trial Centre at the University of Sydney. Treatment will be allocated randomly using the following stratification parameters: liver-only versus extra-hepatic metastases (at least 60\% of recruited patients will have liver-only metastases); the extent of tumour involvement of the liver (classed as $\leq 25 \%$ or $>25 \%$ tumour involvement determined by CT scan, and based upon the tumour involvement groupings used by Gray et al. [24]); planned use of bevacizumab with chemotherapy; and investigational centre.

\section{Protocol treatment}

Systemic chemotherapy must start within 28 days of randomisation. Treatment cycles are described in Figure 2. All patients will be monitored until death or for a minimum of 5 years. Patients randomised to the intervention arm will require a hepatic angiogram and a liver-to-lung 
Table 1 Patient eligibility criteria for SIRFLOX study

\section{Inclusion criteria}

- Written informed consent provided.

- Aged $\geq 18$ years with histologically confirmed adenocarcinoma of the colon or rectum (with or without the primary tumour in situ).

- Proven liver metastases.

- WHO performance status of $0-1$.

- Life expectancy of $\geq 3$ months.

- Patients with additional limited extra-hepatic metastases in the lung or lymph nodes (fewer than 5 nodules $\leq 1 \mathrm{~cm}$ diameter or a single nodule $\leq 1.7 \mathrm{~cm}$ diameter in the lung, and lymph node involvement in a single anatomical area $<2 \mathrm{~cm}$ diameter) with the aim of these patients being $<40 \%$ of the total number of patients recruited (but not being excluded even if they account for more than this proportion).

- Chemotherapy-naïve for mCRC, but previous adjuvant systemic chemotherapy for primary CRC or neoadjuvant chemo-radiotherapy to the pelvis more than 6 months before recruitment are permitted.

- Deemed suitable for either treatment regimen by the investigator.

- Adequate haematological, renal and hepatic function.

- Using an acceptable method of contraception.

shunt study before the SIRT procedure to determine their suitability to receive this treatment. The prescribed activity of SIR-Spheres will be determined from the patient's body surface area (BSA), the percentage tumour involvement, and the magnitude of liver-to-lung shunting (see Table 2).

The dose of bevacizumab administered in the study will be according to standard institutional protocols (usually $5-10 \mathrm{mg} / \mathrm{kg}$ ) and should be infused on the first day of each chemotherapy cycle, commencing with cycle 1 in the control arm. In the intervention arm, bevacizumab should be withheld until at least cycle 4 to mitigate the risk of additive toxicity should the non-targeted delivery of SIR-Spheres to the gastrointestinal tract occur. If non-targeted delivery is suspected, then gastroduodenoscopy will be undertaken before the initiation of bevacizumab therapy. If gastroduodenoscopy reveals an ulcer with biopsy-proven microspheres present, bevacizumab will be withheld until resolution of the ulcer.

In both arms, if following treatment response the patient is deemed a candidate for surgical resection, and

\section{Exclusion criteria}

- Evidence of ascites, cirrhosis, portal hypertension, main portal venous tumour involvement or main portal venous thrombosis.

- Previous radiation therapy to the upper abdomen.

- Non-malignant disease that renders patients unsuitable for the study treatment.

- Grade $>1$ peripheral neuropathy (NCl-CTCv3).

- Previous dose-limiting toxicity associated with adjuvant 5-FU or oxaliplatin chemotherapy.

- Pregnancy or breast-feeding.

- Current or history of cancer other than adequately treated non-melanoma skin cancer or carcinoma in situ of the cervix.

- Allergy to non-ionic contrast agents. the patient undergoes surgical resection and/or complete ablation of their primary and metastatic cancer, adjuvant cycles of protocol mFOLFOX $6 \pm$ bevacizumab will be continued for a minimum of 12 cycles (including preoperative cycles).

\section{Outcome measures}

The primary outcome measure of the SIRFLOX study is a comparison between treatment arms of PFS. Secondary outcomes will include: PFS in the liver; OS; tumour response rate (liver and any site); health-related quality of life (HRQoL); toxicity and safety; and liver resection rate.

\section{Outcome definitions}

OS is defined as the time from the date of randomisation to death from any cause. Patients lost to follow-up, withdrawn, or alive at study completion will be censored at the last date that the patient is known to be alive. PFS is defined as the time from the date of randomisation to confirmation of disease progression at any site (RECIST version 1.0 guidelines [25]) or death from any cause if

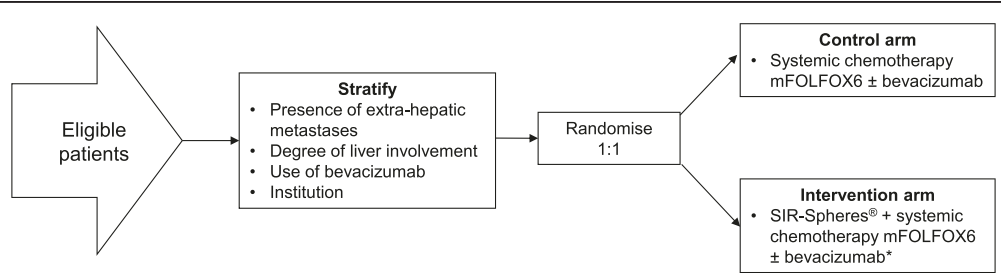

Figure 1 Overview of SIRFLOX study design. Figure footnote: * Bevacizumab, at the investigator's discretion, but not until cycle 4. 


\section{TREATMENT ARM A:}

\begin{tabular}{|c|c|}
\hline $\begin{array}{l}\text { All cycles: } \\
\text { D1 }\end{array}$ & $\begin{array}{l}5-F U \text { bolus } \\
400 \mathrm{mg} / \mathrm{m}^{2}\end{array}$ \\
\hline $\begin{array}{c}\text { LV } \\
200 \mathrm{mg} / \mathrm{m}^{2}\end{array}$ & $\begin{array}{c}\text { 5-FU continuous infusion } \\
2400 \mathrm{mg} / \mathrm{m}^{2}\end{array}$ \\
\hline $\begin{array}{l}\text { oxaliplatin } \\
85 \mathrm{mg} / \mathrm{m}^{2}\end{array}$ & $\begin{array}{c}\text { bevacizumab } \\
5-10 \mathrm{mg} / \mathrm{kg}\end{array}$ \\
\hline
\end{tabular}

Cycles are repeated every 2 weeks until:

- There is unacceptable toxicity.

- Evidence of tumour progression at any site determined by CT/MRI scan, X-ray, ultrasound, or clinical examination.

- The patient requests an end to treatment.

- Complete surgical resection or ablation of primary and metastatic cancerous lesions.

- Or dose-limiting peripheral neuropathy (chemotherapy must continue with the same doses and regimen of 5-FU/LV alone).

\section{TREATMENT ARM B:}

Cycles 1-3:

D1 $\quad \downarrow \begin{aligned} & 5-F U \text { bolus } \\ & 400 \mathrm{mg} / \mathrm{m}^{2}\end{aligned}$

D3/4 Cycle 1 only

\begin{tabular}{|c|c|}
\hline $\mathbf{L V}$ & $\mathbf{5 - F U}$ continuous infusion \\
$200 \mathrm{mg} / \mathrm{m}^{2}$ & $2400 \mathrm{mg} / \mathrm{m}^{2}$
\end{tabular}$\quad$\begin{tabular}{c|} 
SIR-Spheres \\
mBSA dosimetry
\end{tabular}

oxaliplatin

$60 \mathrm{mg} / \mathrm{m}^{2}$

$0 \mathrm{~h} \quad 2 \mathrm{~h} \quad 46 \mathrm{~h}$

Cycles 4+: $\quad$ 5-FU bolus

D1 $400 \mathrm{mg} / \mathrm{m}^{2}$

\begin{tabular}{|c|c|}
\hline $\begin{array}{c}\text { LV } \\
200 \mathrm{mg} / \mathrm{m}^{2}\end{array}$ & $\begin{array}{c}\text { 5-FU continuous infusion } \\
2400 \mathrm{mg} / \mathrm{m}^{2}\end{array}$ \\
\hline $\begin{array}{c}\text { oxaliplatin } \\
85 \mathrm{mg} / \mathrm{m}^{2}\end{array}$ & $\begin{array}{c}\text { bevacizumab } \\
5-10 \mathrm{mg} / \mathrm{kg}\end{array}$ \\
\hline
\end{tabular}

Cycles are repeated every 2 weeks until:

- There is unacceptable toxicity.

- Evidence of tumour progression at any site determined by CT/MRI scan, X-ray, ultrasound, or clinical examination.

- The patient requests an end to treatment.

- Complete surgical resection or ablation of primary and metastatic cancerous lesions.

- Or dose-limiting peripheral neuropathy (chemotherapy must continue with the same doses and regimen of 5-FU/LV alone).

Figure 2 Treatment received as part of the SIRFLOX study. Figure footnote: "Bevacizumab can be added at the investigator's discretion starting at cycle 1 (or according to the institutional protocol). 'Bevacizumab can be added at the investigator's discretion but should not be initiated until cycle 4 (or according to the institutional protocol). If leucovorin is not available, levofolinic acid can be used at a dose of $100 \mathrm{mg} / \mathrm{m}^{2}$. If a centre considers leucovorin $400 \mathrm{mg} / \mathrm{m}^{2}$ the standard dose, then this will be allowed at the investigator's discretion. LV=Leucovorin; 5-FU =5-Fluorouracil.

this occurs before disease progression is documented. Patients who change treatment for reasons other than progression (other than patients who are deemed suitable for surgery) will be censored at change of treatment. PFS and tumour response rate will be determined from serial CT scans using RECIST version 1.0 criteria. Centralised assessment of CT scans and tumour response will be conducted by two independent, board-certified radiologists. Cases of disagreement in the judgment of PFS by the two readers will be adjudicated by a medical oncologist based on both radiological and clinical criteria. The PFS based upon the centralised review constitutes the primary endpoint.

HRQoL will be measured using two questionnaires, the EQ-5D and the EORTC QLQ-30. Adverse events (AEs) and Serious Adverse Events (SAEs) will be collected in accordance with ISO14155 and the International Conference on Harmonisation (ICH) guidelines, and will be rated according to Common Terminology Criteria for Adverse Events (CTCAE) v3.0 and the relationship to 
Table 2 Administered dose calculator used in the SIRFLOX study

\begin{tabular}{|c|c|c|c|c|c|c|c|c|c|c|c|c|c|c|c|c|}
\hline \multirow[b]{2}{*}{ BSA } & \multicolumn{16}{|c|}{ Percentage tumour involvement } \\
\hline & $0-5$ & $6-10$ & 11-15 & $16-20$ & $21-25$ & $26-30$ & $31-35$ & $36-40$ & 41-45 & $46-50$ & $51-55$ & $56-60$ & $61-65$ & $66-70$ & 71-75 & $76-80$ \\
\hline & \multicolumn{16}{|c|}{$0-10 \%$ lung breakthrough } \\
\hline $1.30-1.35$ & 0.7 & 0.8 & 1.0 & 1.2 & 1.3 & 1.4 & 1.5 & 1.5 & 1.5 & 1.5 & 1.4 & 1.3 & 1.3 & 1.2 & 1.1 & 1.1 \\
\hline $1.36-1.40$ & 0.7 & 0.9 & 1.0 & 1.2 & 1.3 & 1.4 & 1.5 & 1.5 & 1.5 & 1.5 & 1.5 & 1.4 & 1.3 & 1.2 & 1.2 & 1.1 \\
\hline $1.41-1.45$ & 0.7 & 0.9 & 1.1 & 1.2 & 1.4 & 1.5 & 1.6 & 1.6 & 1.6 & 1.6 & 1.5 & 1.4 & 1.4 & 1.3 & 1.2 & 1.2 \\
\hline $1.46-1.50$ & 0.8 & 0.9 & 1.1 & 1.3 & 1.4 & 1.5 & 1.6 & 1.7 & 1.7 & 1.6 & 1.6 & 1.5 & 1.4 & 1.3 & 1.3 & 1.2 \\
\hline $1.51-1.55$ & 0.8 & 1.0 & 1.1 & 1.3 & 1.5 & 1.6 & 1.7 & 1.7 & 1.7 & 1.7 & 1.6 & 1.5 & 1.5 & 1.4 & 1.3 & 1.2 \\
\hline $1.56-1.60$ & 0.8 & 1.0 & 1.2 & 1.4 & 1.5 & 1.6 & 1.7 & 1.8 & 1.8 & 1.7 & 1.7 & 1.6 & 1.5 & 1.4 & 1.3 & 1.3 \\
\hline $1.61-1.65$ & 0.8 & 1.0 & 1.2 & 1.4 & 1.6 & 1.7 & 1.8 & 1.8 & 1.8 & 1.8 & 1.7 & 1.6 & 1.6 & 1.5 & 1.4 & 1.3 \\
\hline $1.66-1.70$ & 0.9 & 1.1 & 1.3 & 1.4 & 1.6 & 1.7 & 1.8 & 1.9 & 1.9 & 1.8 & 1.8 & 1.7 & 1.6 & 1.5 & 1.4 & 1.4 \\
\hline $1.71-1.75$ & 0.9 & 1.1 & 1.3 & 1.5 & 1.7 & 1.8 & 1.9 & 1.9 & 1.9 & 1.9 & 1.8 & 1.7 & 1.6 & 1.5 & 1.5 & 1.4 \\
\hline $1.76-1.80$ & 0.9 & 1.1 & 1.3 & 1.5 & 1.7 & 1.8 & 1.9 & 2.0 & 2.0 & 1.9 & 1.9 & 1.8 & 1.7 & 1.6 & 1.5 & 1.4 \\
\hline $1.81-1.85$ & 0.9 & 1.1 & 1.4 & 1.6 & 1.8 & 1.9 & 2.0 & 2.0 & 2.0 & 2.0 & 1.9 & 1.8 & 1.7 & 1.6 & 1.5 & 1.5 \\
\hline $1.86-1.90$ & 1.0 & 1.2 & 1.4 & 1.6 & 1.8 & 1.9 & 2.0 & 2.1 & 2.1 & 2.1 & 2.0 & 1.9 & 1.8 & 1.7 & 1.6 & 1.5 \\
\hline $1.91-1.95$ & 1.0 & 1.2 & 1.4 & 1.7 & 1.9 & 2.0 & 2.1 & 2.1 & 2.1 & 2.1 & 2.0 & 1.9 & 1.8 & 1.7 & 1.6 & 1.6 \\
\hline $1.96-2.00$ & 1.0 & 1.2 & 1.5 & 1.7 & 1.9 & 2.1 & 2.2 & 2.2 & 2.2 & 2.2 & 2.1 & 2.0 & 1.9 & 1.8 & 1.7 & 1.6 \\
\hline $2.01-2.05$ & 1.0 & 1.3 & 1.5 & 1.7 & 1.9 & 2.1 & 2.2 & 2.3 & 2.3 & 2.2 & 2.1 & 2.0 & 1.9 & 1.8 & 1.7 & 1.6 \\
\hline $2.06-2.10$ & 1.1 & 1.3 & 1.6 & 1.8 & 2.0 & 2.2 & 2.3 & 2.3 & 2.3 & 2.3 & 2.2 & 2.1 & 2.0 & 1.9 & 1.8 & 1.7 \\
\hline $2.11-2.15$ & 1.1 & 1.3 & 1.6 & 1.8 & 2.0 & 2.2 & 2.3 & 2.4 & 2.4 & 2.3 & 2.2 & 2.1 & 2.0 & 1.9 & 1.8 & 1.7 \\
\hline $2.16-2.20$ & 1.1 & 1.4 & 1.6 & 1.9 & 2.1 & 2.3 & 2.4 & 2.4 & 2.4 & 2.4 & 2.3 & 2.2 & 2.1 & 1.9 & 1.8 & 1.8 \\
\hline $2.21-2.25$ & 1.1 & 1.4 & 1.7 & 1.9 & 2.1 & 2.3 & 2.4 & 2.5 & 2.5 & 2.4 & 2.3 & 2.2 & 2.1 & 2.0 & 1.9 & 1.8 \\
\hline $2.26-2.30$ & 1.2 & 1.4 & 1.7 & 2.0 & 2.2 & 2.4 & 2.5 & 2.5 & 2.5 & 2.5 & 2.4 & 2.3 & 2.2 & 2.0 & 1.9 & 1.8 \\
\hline $2.31-2.35$ & 1.2 & 1.5 & 1.7 & 2.0 & 2.2 & 2.4 & 2.5 & 2.6 & 2.6 & 2.5 & 2.5 & 2.3 & 2.2 & 2.1 & 2.0 & 1.9 \\
\hline $2.36-2.40$ & 1.2 & 1.5 & 1.8 & 2.0 & 2.3 & 2.5 & 2.6 & 2.6 & 2.6 & 2.6 & 2.5 & 2.4 & 2.3 & 2.1 & 2.0 & 1.9 \\
\hline $2.41-2.45$ & 1.2 & 1.5 & 1.8 & 2.1 & 2.3 & 2.5 & 2.6 & 2.7 & 2.7 & 2.6 & 2.6 & 2.4 & 2.3 & 2.2 & 2.0 & 1.9 \\
\hline \multirow[t]{2}{*}{$2.46-2.50$} & 1.3 & 1.5 & 1.8 & 2.1 & 2.4 & 2.6 & 2.7 & 2.8 & 2.8 & 2.7 & 2.6 & 2.5 & 2.4 & 2.2 & 2.1 & 2.0 \\
\hline & \multicolumn{16}{|c|}{$11-15 \%$ lung breakthrough } \\
\hline $1.30-1.35$ & 0.7 & 0.8 & 1.0 & 1.2 & 1.3 & 1.4 & 1.5 & 1.5 & 1.5 & 1.5 & 1.4 & 1.3 & 1.3 & 1.2 & 1.1 & 1.1 \\
\hline $1.36-1.40$ & 0.7 & 0.9 & 1.0 & 1.2 & 1.3 & 1.4 & 1.5 & 1.5 & 1.5 & 1.5 & 1.5 & 1.4 & 1.3 & 1.2 & 1.2 & 1.1 \\
\hline $1.41-1.45$ & 0.7 & 0.9 & 1.1 & 1.2 & 1.4 & 1.5 & 1.6 & 1.6 & 1.6 & 1.6 & 1.5 & 1.4 & 1.4 & 1.3 & 1.2 & 1.2 \\
\hline $1.46-1.50$ & 0.8 & 0.9 & 1.1 & 1.3 & 1.4 & 1.5 & 1.6 & 1.7 & 1.7 & 1.6 & 1.6 & 1.5 & 1.4 & 1.3 & 1.3 & 1.2 \\
\hline $1.51-1.55$ & 0.8 & 1.0 & 1.1 & 1.3 & 1.5 & 1.6 & 1.7 & 1.7 & 1.7 & 1.7 & 1.6 & 1.5 & 1.5 & 1.4 & 1.3 & 1.2 \\
\hline $1.56-1.60$ & 0.8 & 1.0 & 1.2 & 1.4 & 1.5 & 1.6 & 1.7 & 1.8 & 1.8 & 1.7 & 1.7 & 1.6 & 1.5 & 1.4 & 1.3 & 1.3 \\
\hline $1.61-1.65$ & 0.8 & 1.0 & 1.2 & 1.4 & 1.6 & 1.7 & 1.8 & 1.8 & 1.8 & 1.8 & 1.7 & 1.6 & 1.6 & 1.5 & 1.4 & 1.3 \\
\hline $1.66-1.70$ & 0.9 & 1.1 & 1.3 & 1.4 & 1.6 & 1.7 & 1.8 & 1.9 & 1.9 & 1.8 & 1.8 & 1.7 & 1.6 & 1.5 & 1.4 & 1.4 \\
\hline $1.71-1.75$ & 0.9 & 1.1 & 1.3 & 1.5 & 1.7 & 1.8 & 1.9 & 1.9 & 1.9 & 1.9 & 1.8 & 1.7 & 1.6 & 1.5 & 1.5 & 1.4 \\
\hline $1.76-1.80$ & 0.9 & 1.1 & 1.3 & 1.5 & 1.7 & 1.8 & 1.9 & 2.0 & 2.0 & 1.9 & 1.9 & 1.8 & 1.7 & 1.6 & 1.5 & 1.4 \\
\hline $1.81-1.85$ & 0.9 & 1.1 & 1.4 & 1.6 & 1.8 & 1.9 & 2.0 & 2.0 & 2.0 & 2.0 & 1.9 & 1.8 & 1.7 & 1.6 & 1.5 & 1.5 \\
\hline $1.86-1.90$ & 1.0 & 1.2 & 1.4 & 1.6 & 1.8 & 1.9 & 2.0 & 2.0 & 2.0 & 2.0 & 2.0 & 1.9 & 1.8 & 1.7 & 1.6 & 1.5 \\
\hline $1.91-1.95$ & 1.0 & 1.2 & 1.4 & 1.7 & 1.9 & 2.0 & 2.0 & 2.0 & 2.0 & 2.0 & 2.0 & 1.9 & 1.8 & 1.7 & 1.6 & 1.6 \\
\hline $1.96-2.00$ & 1.0 & 1.2 & 1.5 & 1.7 & 1.9 & 2.0 & 2.0 & 2.0 & 2.0 & 2.0 & 2.0 & 2.0 & 1.9 & 1.8 & 1.7 & 1.6 \\
\hline $2.01-2.05$ & 1.0 & 1.3 & 1.5 & 1.7 & 1.9 & 2.0 & 2.0 & 2.0 & 2.0 & 2.0 & 2.0 & 2.0 & 1.9 & 1.8 & 1.7 & 1.6 \\
\hline $2.06-2.10$ & 1.1 & 1.3 & 1.6 & 1.8 & 2.0 & 2.0 & 2.0 & 2.0 & 2.0 & 2.0 & 2.0 & 2.0 & 2.0 & 1.9 & 1.8 & 1.7 \\
\hline $2.11-2.15$ & 1.1 & 1.3 & 1.6 & 1.8 & 2.0 & 2.0 & 2.0 & 2.0 & 2.0 & 2.0 & 2.0 & 2.0 & 2.0 & 1.9 & 1.8 & 1.7 \\
\hline
\end{tabular}


Table 2 Administered dose calculator used in the SIRFLOX study (Continued)

\begin{tabular}{|c|c|c|c|c|c|c|c|c|c|c|c|c|c|c|c|c|}
\hline $2.16-2.20$ & 1.1 & 1.4 & 1.6 & 1.9 & 2.0 & 2.0 & 2.0 & 2.0 & 2.0 & 2.0 & 2.0 & 2.0 & 2.0 & 1.9 & 1.8 & 1.8 \\
\hline $2.21-2.25$ & 1.1 & 1.4 & 1.7 & 1.9 & 2.0 & 2.0 & 2.0 & 2.0 & 2.0 & 2.0 & 2.0 & 2.0 & 2.0 & 2.0 & 1.9 & 1.8 \\
\hline $2.26-2.30$ & 1.2 & 1.4 & 1.7 & 2.0 & 2.0 & 2.0 & 2.0 & 2.0 & 2.0 & 2.0 & 2.0 & 2.0 & 2.0 & 2.0 & 1.9 & 1.8 \\
\hline $2.31-2.35$ & 1.2 & 1.5 & 1.7 & 2.0 & 2.0 & 2.0 & 2.0 & 2.0 & 2.0 & 2.0 & 2.0 & 2.0 & 2.0 & 2.0 & 2.0 & 1.9 \\
\hline $2.36-2.40$ & 1.2 & 1.5 & 1.8 & 2.0 & 2.0 & 2.0 & 2.0 & 2.0 & 2.0 & 2.0 & 2.0 & 2.0 & 2.0 & 2.0 & 2.0 & 1.9 \\
\hline $2.41-2.45$ & 1.2 & 1.5 & 1.8 & 2.0 & 2.0 & 2.0 & 2.0 & 2.0 & 2.0 & 2.0 & 2.0 & 2.0 & 2.0 & 2.0 & 2.0 & 1.9 \\
\hline $2.46-2.50$ & 1.3 & 1.5 & 1.8 & 2.0 & 2.0 & 2.0 & 2.0 & 2.0 & 2.0 & 2.0 & 2.0 & 2.0 & 2.0 & 2.0 & 2.0 & 2.0 \\
\hline \multicolumn{17}{|c|}{$16-20 \%$ lung breakthrough } \\
\hline $1.30-1.35$ & 0.7 & 0.8 & 1.0 & 1.2 & 1.3 & 1.4 & 1.5 & 1.5 & 1.5 & 1.5 & 1.4 & 1.3 & 1.3 & 1.2 & 1.1 & 1.1 \\
\hline $1.36-1.40$ & 0.7 & 0.9 & 1.0 & 1.2 & 1.3 & 1.4 & 1.5 & 1.5 & 1.5 & 1.5 & 1.5 & 1.4 & 1.3 & 1.2 & 1.2 & 1.1 \\
\hline $1.41-1.45$ & 0.7 & 0.9 & 1.1 & 1.2 & 1.4 & 1.5 & 1.5 & 1.5 & 1.5 & 1.5 & 1.5 & 1.4 & 1.4 & 1.3 & 1.2 & 1.2 \\
\hline $1.46-1.50$ & 0.8 & 0.9 & 1.1 & 1.3 & 1.4 & 1.5 & 1.5 & 1.5 & 1.5 & 1.5 & 1.5 & 1.5 & 1.4 & 1.3 & 1.3 & 1.2 \\
\hline $1.51-1.55$ & 0.8 & 1.0 & 1.1 & 1.3 & 1.5 & 1.5 & 1.5 & 1.5 & 1.5 & 1.5 & 1.5 & 1.5 & 1.5 & 1.4 & 1.3 & 1.2 \\
\hline $1.56-1.60$ & 0.8 & 1.0 & 1.2 & 1.4 & 1.5 & 1.5 & 1.5 & 1.5 & 1.5 & 1.5 & 1.5 & 1.5 & 1.5 & 1.4 & 1.3 & 1.3 \\
\hline $1.61-1.65$ & 0.8 & 1.0 & 1.2 & 1.4 & 1.5 & 1.5 & 1.5 & 1.5 & 1.5 & 1.5 & 1.5 & 1.5 & 1.5 & 1.5 & 1.4 & 1.3 \\
\hline $1.66-1.70$ & 0.9 & 1.1 & 1.3 & 1.4 & 1.5 & 1.5 & 1.5 & 1.5 & 1.5 & 1.5 & 1.5 & 1.5 & 1.5 & 1.5 & 1.4 & 1.4 \\
\hline $1.71-1.75$ & 0.9 & 1.1 & 1.3 & 1.5 & 1.5 & 1.5 & 1.5 & 1.5 & 1.5 & 1.5 & 1.5 & 1.5 & 1.5 & 1.5 & 1.5 & 1.4 \\
\hline $1.76-1.80$ & 0.9 & 1.1 & 1.3 & 1.5 & 1.5 & 1.5 & 1.5 & 1.5 & 1.5 & 1.5 & 1.5 & 1.5 & 1.5 & 1.5 & 1.5 & 1.4 \\
\hline $1.81-1.85$ & 0.9 & 1.1 & 1.4 & 1.5 & 1.5 & 1.5 & 1.5 & 1.5 & 1.5 & 1.5 & 1.5 & 1.5 & 1.5 & 1.5 & 1.5 & 1.5 \\
\hline $1.86-1.90$ & 1.0 & 1.2 & 1.4 & 1.5 & 1.5 & 1.5 & 1.5 & 1.5 & 1.5 & 1.5 & 1.5 & 1.5 & 1.5 & 1.5 & 1.5 & 1.5 \\
\hline $1.91-1.95$ & 1.0 & 1.2 & 1.4 & 1.5 & 1.5 & 1.5 & 1.5 & 1.5 & 1.5 & 1.5 & 1.5 & 1.5 & 1.5 & 1.5 & 1.5 & 1.5 \\
\hline $1.96-2.00$ & 1.0 & 1.2 & 1.5 & 1.5 & 1.5 & 1.5 & 1.5 & 1.5 & 1.5 & 1.5 & 1.5 & 1.5 & 1.5 & 1.5 & 1.5 & 1.5 \\
\hline $2.01-2.05$ & 1.0 & 1.3 & 1.5 & 1.5 & 1.5 & 1.5 & 1.5 & 1.5 & 1.5 & 1.5 & 1.5 & 1.5 & 1.5 & 1.5 & 1.5 & 1.5 \\
\hline $2.06-2.10$ & 1.1 & 1.3 & 1.5 & 1.5 & 1.5 & 1.5 & 1.5 & 1.5 & 1.5 & 1.5 & 1.5 & 1.5 & 1.5 & 1.5 & 1.5 & 1.5 \\
\hline $2.11-2.15$ & 1.1 & 1.3 & 1.5 & 1.5 & 1.5 & 1.5 & 1.5 & 1.5 & 1.5 & 1.5 & 1.5 & 1.5 & 1.5 & 1.5 & 1.5 & 1.5 \\
\hline $2.16-2.20$ & 1.1 & 1.4 & 1.5 & 1.5 & 1.5 & 1.5 & 1.5 & 1.5 & 1.5 & 1.5 & 1.5 & 1.5 & 1.5 & 1.5 & 1.5 & 1.5 \\
\hline $2.21-2.25$ & 1.1 & 1.4 & 1.5 & 1.5 & 1.5 & 1.5 & 1.5 & 1.5 & 1.5 & 1.5 & 1.5 & 1.5 & 1.5 & 1.5 & 1.5 & 1.5 \\
\hline $2.26-2.30$ & 1.2 & 1.4 & 1.5 & 1.5 & 1.5 & 1.5 & 1.5 & 1.5 & 1.5 & 1.5 & 1.5 & 1.5 & 1.5 & 1.5 & 1.5 & 1.5 \\
\hline $2.31-2.35$ & 1.2 & 1.5 & 1.5 & 1.5 & 1.5 & 1.5 & 1.5 & 1.5 & 1.5 & 1.5 & 1.5 & 1.5 & 1.5 & 1.5 & 1.5 & 1.5 \\
\hline $2.36-2.40$ & 1.2 & 1.5 & 1.5 & 1.5 & 1.5 & 1.5 & 1.5 & 1.5 & 1.5 & 1.5 & 1.5 & 1.5 & 1.5 & 1.5 & 1.5 & 1.5 \\
\hline $2.41-2.45$ & 1.2 & 1.5 & 1.5 & 1.5 & 1.5 & 1.5 & 1.5 & 1.5 & 1.5 & 1.5 & 1.5 & 1.5 & 1.5 & 1.5 & 1.5 & 1.5 \\
\hline $2.46-2.50$ & 1.3 & 1.5 & 1.5 & 1.5 & 1.5 & 1.5 & 1.5 & 1.5 & 1.5 & 1.5 & 1.5 & 1.5 & 1.5 & 1.5 & 1.5 & 1.5 \\
\hline
\end{tabular}

Dose values are given in $\mathrm{GBq}$.

$B S A=$ Body surface area.

protocol therapy will be rated as none, unlikely, possible or probable.

After 360 patients (80\% of the intended sample size) have completed 15 months of follow-up, at least 300 progressions are expected. The actual pooled event rate will be assessed at this time by an independent data monitoring and safety monitoring committee (IDMC) to determine if the study should continue as planned.

\section{Assessment procedures and timing}

All patients will be assessed by the criteria summarised in Table 3. Additional non-study assessments are permitted at the discretion of the treating investigator.

\section{Sample size calculation and statistical considerations}

The potential benefit of adding bevacizumab to FOLFOX is approximately a 4-week increase in median PFS [17]. Based on previously reported data, a median PFS time of 8.5 months may be expected with FOLFOX in patients with liver-only or liver-dominant mCRC (i.e., in the control arm); and therefore, with the addition of bevacizumab, median PFS time could be estimated at 9.4 months. Based on previously reported data of SIRT plus hepatic artery chemotherapy (median PFS of 16 months [24]) and SIRT plus first-line 5-FU/LV chemotherapy (median PFS of 18.6 months [22]), a conservative estimation of median PFS in the intervention arm would be 15 months for 
Table 3 SIRFLOX study assessment schedule

\begin{tabular}{|c|c|c|c|c|c|}
\hline \multirow[b]{2}{*}{ Evaluation/examination } & \multirow{2}{*}{$\begin{array}{c}\text { Screening } \\
\text { ( } \leq 28 \mathrm{~d} \text { before randomisation) }\end{array}$} & \multicolumn{3}{|c|}{ During chemotherapy } & \multirow{2}{*}{$\begin{array}{l}\text { Post-progression } \\
\text { follow-up } \\
\text { (every } 12 \text { weeks) }\end{array}$} \\
\hline & & Day 1 & Day 3 or 4 of cycle 1 & Every 2 weeks \pm 1 week $^{\mathrm{a}}$ & \\
\hline Informed consent & $x$ & & & & \\
\hline Demographics & $x$ & & & & \\
\hline Medical history & $x$ & & & & \\
\hline Concomitant illnesses & $x$ & & & & \\
\hline Concurrent medications & $x$ & $x$ & $x$ & $x$ & \\
\hline $\begin{array}{l}\text { Clinical assessment and } \\
\text { physical examination }\end{array}$ & $x$ & $x$ & & $x$ & \\
\hline Performance status & $x$ & $x$ & & $x$ & \\
\hline Haematology ${ }^{\mathrm{b}}$ & $x$ & $x$ & & $x$ & \\
\hline Biochemistry ${ }^{c}$ & $x$ & $x$ & & $x$ & \\
\hline Pregnancy test & $x$ & & & & \\
\hline Serum CEA & $x$ & & & $x^{d}$ & \\
\hline $\mathrm{CT}$ of chest/abdomen/pelvis & $x$ & & & $x^{e}$ & $x$ \\
\hline Assessment for resection & $x$ & & & $x^{e}$ & \\
\hline Hepatic angiogram $^{f}$ & & $x^{g}$ & & & \\
\hline${ }^{99 \mathrm{~m}}$ TC-MAA lung shunt study ${ }^{f}$ & & $x^{g}$ & & & \\
\hline Adverse events & From cons & nt until & 8 days after the last dose & of protocol chemotherapy & \\
\hline EQ-5D HRQoL & $x$ & & & $x^{h}$ & \\
\hline EORTC QLQ-C30 HRQOL & $x$ & & & $x^{i}$ & \\
\hline $\begin{array}{l}\text { Ongoing review of treatment } \\
\text { and survival }\end{array}$ & & & & & $x$ \\
\hline
\end{tabular}

${ }^{\mathrm{a}}$ Before each cycle of chemotherapy unless otherwise stated.

${ }^{\mathrm{b}}$ Measurement of haemoglobin, platelets, white blood cells, absolute neutrophils and absolute lymphocytes.

'Urea, creatinine, liver enzymes, alkaline phosphatase, bilirubin and albumin.

dEvery 4 weeks.

eEvery 8 weeks.

Intervention arm only.

${ }^{9} 7$ days \pm 4 days before SIRT.

${ }^{h} E Q-5 D$ questionnaire completed at $3,6,12,24,36$ months, and annually thereafter.

i 4 weeks and 12 months after starting treatment.

$C E A=$ Carcinoembryonic antigen; $C T=$ Computed tomography.

patients with liver-only metastases and 10 months for patients with liver-dominant metastatic disease. Using these data and assuming a liver-dominant:liver-only ratio of 40:60, a sample size of at least 450 patients for the SIRFLOX study was estimated to detect an increase in the median PFS from 9.4 months to 12.5 months with $80 \%$ power and $95 \%$ confidence.

Primary and secondary endpoints will be analysed according to the intention-to-treat (ITT) principle. Response rates will be compared between treatment arms using a test of proportions, and time to event endpoints will be compared using the log-rank test. The primary endpoint will be assessed in the ITT population, and additional analyses will also assess endpoints in sub-groups: no bevacizumab versus with bevacizumab; presence versus absence of extra-hepatic metastases; and tumour involvement of the liver $\leq 25 \%$ versus $>25 \%$. Exploratory analyses will be performed adjusting for prognostic factors in a multivariate analysis framework.

\section{Discussion}

The SIRFLOX study will assess the efficacy and safety of SIRT in combination with FOLFOX-based systemic chemotherapy as first-line treatment of patients with inoperable liver-only or liver-predominant mCRC. To date, efficacy and safety data for this combination are available in a limited number of patients $[23,26]$, and for the use of SIRT in chemotherapy-refractory mCRC [27-29]. Although SIRT has been delivered to more than 35,000 patients in over 600 specialist centres worldwide since 2000, such large-scale studies of this treatment have not been feasible before. However, skilled centres are now numerous enough worldwide to enable recruitment of a large pool of patients for these studies. 
Some aspects of the treatment arms of the SIRFLOX study are worth further discussion. The prescribed activity of SIR-Spheres was determined by the results of the previous dose-escalation study of SIR-Spheres + FOLFOX4 [23]. Furthermore, in patients randomised to receive SIRT in the SIRFLOX study, the dose of oxaliplatin is reduced to $60 \mathrm{mg} / \mathrm{m}^{2}$ for the first three cycles of chemotherapy, and in subsequent cycles is increased to the standard dose of $85 \mathrm{mg} / \mathrm{m}^{2}$. One safety concern is that the oxaliplatin in the chemotherapy regimen is a radio-sensitising agent, which when used in combination with externalbeam radiation therapy results in hepatotoxicity at doses $>60 \mathrm{mg} / \mathrm{m}^{2}$ [30-32]. The earlier dose-escalation study of SIR-Spheres + FOLFOX4 also concluded that oxaliplatin at doses $>60 \mathrm{mg} / \mathrm{m}^{2}$ in the first three cycles of chemotherapy could increase the occurrence of grade 3 and 4 neutropenia [23].

mFOLFOX6 chemotherapy has become widely adopted for the treatment of $\mathrm{mCRC}$, largely because it does not require the day-2 bolus injections of 5 -FU that is part of FOLFOX4 and is therefore more convenient. Although previous trials have shown that first-line SIR-Spheres plus chemotherapy can significantly increase time-to-progression and survival in patients with mCRC $[22,24]$, these used chemotherapy regimens that are now outdated in the management of mCRC. This provides the rationale for choosing mFOLFOX6 in the study. mFOLFOX6 includes oxaliplatin doses of $85 \mathrm{mg} / \mathrm{m}^{2}$ rather than the dose of $100 \mathrm{mg} / \mathrm{m}^{2}$ used in FOLFOX6 [33] - thus, this will maximise the time that patients can receive protocol chemotherapy before peripheral neuropathy becomes an issue (which necessitates the removal of oxaliplatin) [34].

Patient stratification in SIRFLOX includes the intention to use bevacizumab. The addition of bevacizumab to chemotherapy regimens may enhance survival times and PFS in patients with $\mathrm{mCRC}[17,21,35,36]$, but little is known about the potential added benefits of primary chemotherapy + bevacizumab + SIRT. Data on bevacizumab and the other biological agents such as cetuximab and panitumumab for the treatment of liver-only mCRC are limited and sometimes contradictory [37-41], which has made guidance on the optimal first-line treatment strategies difficult and sometimes conflicting [42]. Indeed, despite the initial enthusiasm with targeted biological agents and evidence that they can improve 2-year survival, no gains in 5-year survival have been observed with these agents [43]. The approach of combining systemic chemotherapy \pm biologic agents with targeted radiation therapy may provide enhanced benefits in $\mathrm{mCRC}$.

Another strata that will be assessed in these trials is the absence or presence of extra-hepatic metastases. Although published efficacy data on SIRT and FOLFOX chemotherapy are limited, initial data did indicate considerably longer PFS and OS among patients with liver-only disease [26].
In addition to the SIRFLOX study, SIRT in combination with FOLFOX-based systemic chemotherapy as first-line treatment of patients with inoperable liver-only or liver-predominant $\mathrm{mCRC}$ is being investigated in the FOXFIRE trial. The studies have almost identical protocols, and FOXFIRE has as a primary endpoint an $a$ priori analysis of OS of all patients included in SIRFLOX and FOXFIRE.

A recent consensus statement on systemic cytotoxic and biological therapies for liver metastases from CRC summarised expert recommendations on the management of patients with non-resectable metastatic tumours [44]. In the accompanying editorial [45], Clary et al. identified the need to optimise outcomes of systemic treatment in patients with non-resectable liver metastases as a key question to be addressed. The SIRFLOX study and FOXFIRE trial aim to address this issue in a large patient population and may help provide important new evidence on the use of SIRT early in the therapeutic cascade to enhance PFS and/or OS in this patient population. The use of SIRT with yttrium-90 resin microspheres was not specifically addressed in the consensus statement, presumably due to the paucity of data [44]. Clary et al. highlighted this omission and concluded, "The optimal use of these modalities is undefined and requires further study" [45]. The results from the SIRFLOX study and FOXFIRE trial should further our understanding of SIRT, may help define the optimal use of this treatment modality in $\mathrm{mCRC}$, and may place this treatment option at the forefront of future consensus guidelines.

\section{Additional file}

Additional file 1: Participating centres and ethics committees that have approved the SIRFLOX study. Table of participating centres ethics committees that have approved the SIRFLOX study.

\begin{abstract}
Abbreviations
BSA: Body surface area; CRC: Colorectal cancer; 5-FU: 5-Fluorouracil; HRQOL: Health-related quality of life; ITT: Intention-to-treat; LV: Leucovorin; OS: Overall survival; PFS: Progression-free survival; RECIST: Response evaluation criteria in solid tumours; SIRT: Selective internal radiation therapy.
\end{abstract}

\section{Competing interests}

PG has received honoraria from Sirtex for participation in advisory boards and for giving presentations. VG has received compensation for participation in Advisory Committees from Sirtex. MVB has received consultancy fees from Sirtex. DC is CMO/full time employee of Sirtex Medical Limited. KT is a full time employee of Sirtex Medical Limited. GVH has received compensation for participation in Advisory Committees from Sirtex.

Authors' contributions

All authors were substantially involved in the conception and design of the SIRFLOX study. All authors were involved in drafting or critically reviewing each draft of the manuscript for important intellectual content, and all authors read and approved the final draft of the manuscript for submission. 


\section{Acknowledgements}

The authors thank all investigators in the SIRFLOX Study Group, and in particular the Principal Investigators: Pradip Amin (USA), Bruna Angelelli (Italy), Jacques Balosso (France), Alex Beny (Israel), Daniel Bloomgarden (USA), Eveline Boucher (France), Michael Brown (Australia), Harald-Robert Bruch (Germany), James Bui (USA), Matthew Burge (Australia), Giuseppe Cardaci (Australia), James Carlisle (USA), Yi-Jen Chen (USA), Patrick Chevallier (France), Stephen Clarke (Australia), Andrew Coveler (USA), Michel Craninx (Belgium), Thierry Delanoit (Belgium), Amélie Deleporte (Belgium), Paul Eliadis (Australia), Francis Facchini (USA), Thomas Ferguson (Australia), Michel Ferrante (Belgium), Michael Findlay (New Zealand), Gary Frenette (USA), Jacob Frick (USA), Vinod Ganju (Australia), Michael Garofalo (USA), Karen Geboes (Belgium), Gerald Gehbauer (Germany), Benjamin George (USA), Ravit Geva (Israel), Michael Gordon (USA), Seza Gulac (USA), James Hannigan (USA), Volker Heinemann (Germany), Thomas Helmberger (Germany), Matthew Holtzman (USA), Richard Isaacs (New Zealand), Philip James (Australia), Andreas Kaubisch (USA), Yon-Dschun Ko (Germany), Todd Kooy (USA), Hendrik Kröning (Germany), Frank Lammert (Germany), Winston Liauw (Australia), Samy Louafi (France), Marc de Man (Belgium), Jeffrey Margolis (USA), Robert Martin (USA), Gavin Marx (Australia), Marco Matos (Australia), Els Monsaert (Belgium), Veerle Moons (Belgium), Louise Nott (Australia), Arnd Nusch (Germany), Anne O'Donnell (New Zealand), Howard Ozer (USA), Siddarth Padia (USA), Nick Pavlakis (Australia), Marc Peeters (Belgium), David Perez (New Zealand), Stefan Pluntke (Germany), Marc Polus (Belgium), Alex Powell (Australia), Timothy Price (Australia), David Ransom (Australia), Christine Rebischung (France), Karsten Ridwelski (Germany), Hanno Riess (Germany), Jorge Ramon Riera (Germany), Jens Ricke (Germany), William Rilling (USA), Bridget Robinson (New Zealand), Javier Rodríguez (Spain), Tilmann Sauerbruch (Germany), Michael Savin (USA), Klemens Scheidhauer (Germany), Elyse Schneiderman (USA), Grant Seeger (USA), Eva Segelov (Australia), Einat Shaham Schmueli (Israel), Adi Shani (Israel), Jenny Shannon (Australia), Navesh Sharma (USA), Stephen Shibata (USA), Nimit Singhal (Australia), Denis Smith (France), Randall Smith (USA), Salomon Stemmer (Israel), Oliver Stötzer (Germany), Andrew Strickland (Australia), Julien Taieb (France), Klaus Tatsch (Germany), Eric Terrebonne (France), Thomas Tichler (Israel), Ursula Vehling-Kaiser (Germany), Ruth Vera-Garcia (Spain), Thomas Vogl (Germany), Euan Walpole (Australia), Eric Wang (USA), Samuel Whiting (USA), Ido Wolf (Israel).

This study was sponsored by Sirtex Technology Pty Ltd. The authors would like to acknowledge Bruce Gray for his involvement in the development of the initial protocol. We acknowledge the editorial assistance provided by Martin Gilmour of ESP Bioscience (Crowthorne, UK) funded by Sirtex, during the preparation of this manuscript.

\section{Author details}

${ }^{1}$ Royal Melbourne Hospital, Melbourne, Victoria, Australia. ${ }^{2} \mathrm{NHMRC}$ Clinical Trials Centre, Camperdown, New South Wales, Australia. ${ }^{3}$ Data Reduction LLC, Chester, New Jersey, USA. ${ }^{4}$ Sirtex Medical Limited, North Sydney, New South Wales, Australia. ${ }^{5}$ University of Western Australia, Perth, Western Australia, Australia. ${ }^{6}$ Walter and Eliza Hall Institute Medical Research, Melbourne, Australia.

\section{Received: 24 February 2014 Accepted: 13 November 2014} Published: 1 December 2014

\section{References}

1. Welch JP, Donaldson GA: The clinical correlation of an autopsy study of recurrent colorectal cancer. Ann Surg 1979, 189:496-502.

2. Abbas S, Lam V, Hollands M: Ten-year survival after liver resection for colorectal metastases: systematic review and meta-analysis. ISRN Oncol 2011, 2011:763245.

3. Adam R: Developing strategies for liver metastases from colorectal cancer. Semin Oncol 2007, 34:S7-S11.

4. Fong Y, Fortner J, Sun RL, Brennan MF, Blumgart LH: Clinical score for predicting recurrence after hepatic resection for metastatic colorectal cancer: analysis of 1001 consecutive cases. Ann Surg 1999, 230:309-318. discussion 318-321.

5. Choti MA, Sitzmann JV, Tiburi MF, Sumetchotimetha W, Rangsin R, Schulick RD, Lillemoe KD, Yeo CJ, Cameron JL: Trends in long-term survival following liver resection for hepatic colorectal metastases. Ann Surg 2002, 235:759-766.

6. Stangl R, Altendorf-Hofmann A, Charnley RM, Scheele J: Factors influencing the natural history of colorectal liver metastases. Lancet 1994, 343:1405-1410.

7. Rothbarth J, van de Velde CJ: Treatment of liver metastases of colorectal cancer. Ann Oncol 2005, 16(Suppl 2):ii144-ii149.

8. Berber E, Pelley R, Siperstein AE: Predictors of survival after radiofrequency thermal ablation of colorectal cancer metastases to the liver: a prospective study. J Clin Oncol 2005, 23:1358-1364.

9. Navarra G, Ayav A, Weber JC, Jensen SL, Smadga C, Nicholls JP, Habib NA, Jiao LR: Short- and-long term results of intraoperative radiofrequency ablation of liver metastases. Int J Colorectal Dis 2005, 20:521-528.

10. Van Cutsem E, Nordlinger B, Adam R, Kohne CH, Pozzo C, Poston G, Ychou M, Rougier P, European Colorectal Metastases Treatment G: Towards a pan-European consensus on the treatment of patients with colorectal liver metastases. Eur J Cancer 2006, 42:2212-2221.

11. de Jong MC, Pulitano C, Ribero D, Strub J, Mentha G, Schulick RD, Choti MA, Aldrighetti L, Capussotti L, Pawlik TM: Rates and patterns of recurrence following curative intent surgery for colorectal liver metastasis: an international multi-institutional analysis of 1669 patients. Ann Surg 2009, 250:440-448.

12. Meta-analysis Group In Cancer, Piedbois $P$, Rougier $P$, Buyse M, Pignon J, Ryan L, Hansen R, Zee B, Weinerman B, Pater J, Leichman C, Macdonald J, Benedetti J, Lokich J, Fryer J, Brufman G, Isacson R, Laplanche A, Levy E: Efficacy of intravenous continuous infusion of fluorouracil compared with bolus administration in advanced colorectal cancer. J Clin Oncol 1998, 16:301-308.

13. Saltz LB, Cox JV, Blanke C, Rosen LS, Fehrenbacher L, Moore MJ, Maroun JA, Ackland SP, Locker PK, Pirotta N, Elfring GL, Miller LL: Irinotecan plus fluorouracil and leucovorin for metastatic colorectal cancer. $N$ Engl J Med 2000, 343:905-914.

14. Goldberg RM, Sargent DJ, Morton RF, Fuchs CS, Ramanathan RK, Williamson SK, Findlay BP, Pitot HC, Alberts SR: A randomized controlled trial of fluorouracil plus leucovorin, irinotecan, and oxaliplatin combinations in patients with previously untreated metastatic colorectal cancer. J Clin Oncol 2004, 22:23-30.

15. Tournigand C, Andre T, Achille E, Lledo G, Flesh M, Mery-Mignard D, Quinaux E, Couteau C, Buyse M, Ganem G, Landi B, Colin P, Louvet C, de Gramont A: FOLFIRI followed by FOLFOX6 or the reverse sequence in advanced colorectal cancer: a randomized GERCOR study. J Clin Oncol 2004, 22:229-237.

16. Hurwitz H, Fehrenbacher L, Novotny W, Cartwright T, Hainsworth J, Heim W, Berlin J, Baron A, Griffing S, Holmgren E, Ferrara N, Fyfe G, Rogers B, Ross R, Kabbinavar F: Bevacizumab plus irinotecan, fluorouracil, and leucovorin for metastatic colorectal cancer. N Engl J Med 2004, 350:2335-2342.

17. Saltz LB, Clarke S, Diaz-Rubio E, Scheithauer W, Figer A, Wong R, Koski S, Lichinitser M, Yang TS, Rivera F, Couture F, Sirzen F, Cassidy J: Bevacizumab in combination with oxaliplatin-based chemotherapy as first-line therapy in metastatic colorectal cancer: a randomized phase III study. J Clin Oncol 2008, 26:2013-2019.

18. Folprecht G, Grothey A, Alberts S, Raab HR, Kohne CH: Neoadjuvant treatment of unresectable colorectal liver metastases: correlation between tumour response and resection rates. Ann Oncol 2005, 16:1311-1319.

19. Adam R, Delvart V, Pascal G, Valeanu A, Castaing D, Azoulay D, Giacchetti S, Paule B, Kunstlinger F, Ghemard O, Levi F, Bismuth H: Rescue surgery for unresectable colorectal liver metastases downstaged by chemotherapy: a model to predict long-term survival. Ann Surg 2004, 240:644-657. discussion 657-648.

20. Louvet C, de Gramont A: Colorectal cancer: integrating oxaliplatin. Curr Treat Options Oncol 2003, 4:405-411.

21. Giantonio BJ, Catalano PJ, Meropol NJ, O'Dwyer PJ, Mitchell EP, Alberts SR, Schwartz MA, Benson AB 3rd, Eastern Cooperative Oncology Group Study E: Bevacizumab in combination with oxaliplatin, fluorouracil, and leucovorin (FOLFOX4) for previously treated metastatic colorectal cancer: results from the Eastern Cooperative Oncology Group Study E3200. J Clin Oncol 2007, 25:1539-1544.

22. Van Hazel G, Blackwell A, Anderson J, Price D, Moroz P, Bower G, Cardaci G, Gray B: Randomised phase 2 trial of SIR-Spheres plus fluorouracil/leucovorin chemotherapy versus fluorouracil/leucovorin chemotherapy alone in advanced colorectal cancer. J Surg Oncol 2004, 88:78-85. 
23. Sharma RA, Van Hazel GA, Morgan B, Berry DP, Blanshard K, Price D, Bower G, Shannon JA, Gibbs P, Steward WP: Radioembolization of liver metastases from colorectal cancer using yttrium-90 microspheres with concomitant systemic oxaliplatin, fluorouracil, and leucovorin chemotherapy. J Clin Oncol 2007, 25:1099-1106.

24. Gray B, Van Hazel G, Hope M, Burton M, Moroz P, Anderson J, Gebski V: Randomised trial of SIR-Spheres plus chemotherapy vs. chemotherapy alone for treating patients with liver metastases from primary large bowel cancer. Ann Oncol 2001, 12:1711-1720.

25. Therasse P, Arbuck SG, Eisenhauer EA, Wanders J, Kaplan RS, Rubinstein L, Verweij J, Van Glabbeke M, van Oosterom AT, Christian MC, Gwyther SG: New guidelines to evaluate the response to treatment in solid tumors. European Organization for Research and Treatment of Cancer, National Cancer Institute of the United States, National Cancer Institute of Canada. J Nat/ Cancer Inst 2000, 92:205-216.

26. Kosmider S, Tan TH, Yip D, Dowling R, Lichtenstein M, Gibbs P: Radioembolization in combination with systemic chemotherapy as first-line therapy for liver metastases from colorectal cancer. J Vasc Interv Radiol 2011, 22:780-786.

27. Hendlisz A, Van den Eynde M, Peeters M, Maleux G, Lambert B, Vannoote J, De Keukeleire K, Verslype C, Defreyne L, Van Cutsem E, Delatte P, Delaunoit T, Personeni N, Paesmans M, Van Laethem JL, Flamen P: Phase III trial comparing protracted intravenous fluorouracil infusion alone or with yttrium-90 resin microspheres radioembolization for liver-limited metastatic colorectal cancer refractory to standard chemotherapy. J Clin Oncol 2010, 28:3687-3694.

28. Bester L, Meteling B, Pocock N, Pavlakis N, Chua TC, Saxena A, Morris DL: Radioembolization versus standard care of hepatic metastases: comparative retrospective cohort study of survival outcomes and adverse events in salvage patients. J Vasc Interv Radiol 2012, 23:96-105.

29. Seidensticker R, Denecke T, Kraus P, Seidensticker M, Mohnike K, Fahlke J, Kettner E, Hildebrandt B, Dudeck O, Pech M, Amthauer H, Ricke J: Matched-pair comparison of radioembolization plus best supportive care versus best supportive care alone for chemotherapy refractory liver-dominant colorectal metastases. Cardiovasc Intervent Radiol 2012, 35:1066-1073

30. Khushalani NI, Leichman CG, Proulx G, Nava H, Bodnar L, Klippenstein D, Litwin A, Smith J, Nava E, Pendyala L, Smith P, Greco W, Berdzik J, Douglass $H$, Leichman L: Oxaliplatin in combination with protracted-infusion fluorouracil and radiation: report of a clinical trial for patients with esophageal cancer. J Clin Oncol 2002, 20:2844-2850.

31. Freyer G, Bossard N, Romestaing P, Mornex F, Chapet O, Trillet-Lenoir V, Gerard JP: Addition of oxaliplatin to continuous fluorouracil, I-folinic acid, and concomitant radiotherapy in rectal cancer: the Lyon R 97-03 phase I trial. J Clin Oncol 2001, 19:2433-2438.

32. Aschele C, Friso ML, Pucciarelli S, Lonardi S, Sartor L, Fabris G, Urso ED, Del Bianco P, Sotti G, Lise M, Monfardini S: A phase I-II study of weekly oxaliplatin, 5-fluorouracil continuous infusion and preoperative radiotherapy in locally advanced rectal cancer. Ann Oncol 2005, 16:1140-1146.

33. Cheeseman SL, Joel SP, Chester JD, Wilson G, Dent JT, Richards FJ, Seymour MT: A 'modified de Gramont' regimen of fluorouracil, alone and with oxaliplatin, for advanced colorectal cancer. Br J Cancer 2002, 87:393-399.

34. Cersosimo RJ: Oxaliplatin-associated neuropathy: a review. Ann Pharmacother 2005, 39:128-135.

35. Van Cutsem E, Rivera F, Berry S, Kretzschmar A, Michael M, DiBartolomeo M, Mazier MA, Canon JL, Georgoulias V, Peeters M, Bridgewater J, Cunningham $D, B E A T$ investigators: Safety and efficacy of first-line bevacizumab with FOLFOX, XELOX, FOLFIRI and fluoropyrimidines in metastatic colorectal cancer: the BEAT study. Ann Oncol 2009, 20:1842-1847.

36. Nasti G, Ottaiano A, Berretta M, Delrio P, Izzo F, Cassata A, Romano C, Facchini G, Scala D, Mastro A, Romano G, Perri F, laffaioli RV: Pre-operative chemotherapy for colorectal cancer liver metastases: an update of recent clinical trials. Cancer Chemother Pharmacol 2010, 66:209-218.

37. Van Cutsem E, Kohne CH, Lang I, Folprecht G, Nowacki MP, Cascinu S, Shchepotin I, Maurel J, Cunningham D, Tejpar S, Schlichting M, Zubel A, Celik I, Rougier P, Ciardiello F: Cetuximab plus irinotecan, fluorouracil, and leucovorin as first-line treatment for metastatic colorectal cancer: updated analysis of overall survival according to tumor KRAS and BRAF mutation status. J Clin Oncol 2011, 29:2011-2019.

38. Bokemeyer C, Bondarenko I, Makhson A, Hartmann JT, Aparicio J, de Braud F, Donea S, Ludwig H, Schuch G, Stroh C, Loos AH, Zubel A, Koralewski P:
Fluorouracil, leucovorin, and oxaliplatin with and without cetuximab in the first-line treatment of metastatic colorectal cancer. J Clin Oncol 2009, 27:663-671.

39. Maughan TS, Adams RA, Smith CG, Meade AM, Seymour MT, Wilson RH, Idziaszczyk S, Harris R, Fisher D, Kenny SL, Kay E, Mitchell JK, Madi A, Jasani B, James MD, Bridgewater J, Kennedy MJ, Claes B, Lambrechts D, Kaplan R, Cheadle JP, MRC COIN Trial Investigators: Addition of cetuximab to oxaliplatin-based first-line combination chemotherapy for treatment of advanced colorectal cancer: results of the randomised phase 3 MRC COIN trial. Lancet 2011, 377:2103-2114.

40. Tveit KM, Guren T, Glimelius B, Pfeiffer P, Sorbye H, Pyrhonen S, Sigurdsson F, Kure E, Ikdahl T, Skovlund E, Fokstuen T, Hansen F, Hofsli E, Birkemeyer E, Johnsson A, Starkhammar H, Yilmaz MK, Keldsen, Erdal AB, Dajani O, Dahl O, Christoffersen T': Phase III trial of cetuximab with continuous or intermittent fluorouracil, leucovorin, and oxaliplatin (Nordic FLOX) versus FLOX alone in first-line treatment of metastatic colorectal cancer: the NORDIC-VII study. J Clin Oncol 2012, 30:1755-1762.

41. Zhou SW, Huang YY, Wei Y, Jiang ZM, Zhang YD, Yang Q, Xie DR: No survival benefit from adding cetuximab or panitumumab to oxaliplatin-based chemotherapy in the first-line treatment of metastatic colorectal cancer in KRAS wild type patients: a meta-analysis. PLOS One 2012, 7:e50925.

42. Peeters M, Price T: Biologic therapies in the metastatic colorectal cancer treatment continuum-applying current evidence to clinical practice. Cancer Treat Rev 2012, 38:397-406.

43. Chu E: An update on the current and emerging targeted agents in metastatic colorectal cancer. Clin Colorectal Cancer 2012, 11:1-13.

44. Schwarz RE, Berlin JD, Lenz HJ, Nordlinger B, Rubbia-Brandt L, Choti MA: Systemic cytotoxic and biological therapies of colorectal liver metastases: expert consensus statement. HPB 2013, 15:106-115.

45. Clary BM, Grothey A, Kopetz S, Marsh RD: Systemic cytotoxic and biologic therapies for colorectal cancer liver metastases: expert consensus statement. HPB 2013, 15:116-118.

doi:10.1186/1471-2407-14-897

Cite this article as: Gibbs et al: Selective Internal Radiation Therapy (SIRT) with yttrium-90 resin microspheres plus standard systemic chemotherapy regimen of FOLFOX versus FOLFOX alone as first-line treatment of non-resectable liver metastases from colorectal cancer: the SIRFLOX study. BMC Cancer 2014 14:897.

\section{Submit your next manuscript to BioMed Central and take full advantage of:}

- Convenient online submission

- Thorough peer review

- No space constraints or color figure charges

- Immediate publication on acceptance

- Inclusion in PubMed, CAS, Scopus and Google Scholar

- Research which is freely available for redistribution 